\title{
Analisis Kinerja Simpang Tak Bersinyal Jalan A.H. Nasution dan Jalan Cikadut, Kota Bandung
}

\author{
MUHAMMAD DARYL MARTA PRATAMA, ELKHASNET
}

Jurusan Teknik Sipil Institut Teknologi Nasional

Email: mdaryl31@gmail.com

\begin{abstract}
ABSTRAK
Persimpangan merupakan suatu bagian jalan yang menjadi pusat pertemuan dari berbagai pergerakan arus lalu lintas. Pada tipe simpang tak bersinyal, sering dijumpai titik-titik konflik arus lalu lintas yang mengakibatkan kemacetan arus lalu lintas terutama pada saat jam-jam sibuk. Contoh kasus terdapat di Kota Bandung, terjadi pada persimpangan Jalan A.H. Nasution dan Jalan Cikadut. Lokasi ini dipilih karena selain kemacetan yang disebabkan oleh titik-titik konflik arus lalu lintas yang tidak teratur pada saat jam sibuk, di sekitar jalan pada simpang ini juga merupakan kawasan pertokoan, pemukiman, sekolah dan juga terdapat pom bensin. Berdasarkan permasalahan tersebut, dilakukan perhitungan dan analisis data pada kondisi awal simpang, didapat nilai derajat jenuh (DS) sebesar 0,983 untuk pagi hari dan 0,937 untuk sore hari. Karena hasil perhitungan simpang pada kondisi awal tidak memenuhi syarat MKJI 1997, yaitu DS $<0,85$, maka perlu dilakukan perhitungan ulang dengan beberapa alternatif agar nilai DS bisa memenuhi.
\end{abstract}

Kata kunci: persimpangan, kemacetan, derajat jenuh, MKJI 1997.

\begin{abstract}
Intersection is a part of the road that becomes the center concourse of various traffic flow movements. In the type of unsignalized intersection, there are often traffic flow conflict points which cause traffic jams, especially during rush hour. Examples of cases are in the City of Bandung, occurred at the intersection of A.H. Nasution Street and Cikadut Street. This location was chosen because in addition to congestion caused by irregular traffic flow conflict points during rush hour, around the road at the intersection this is also a shopping area, residential, school and gas station. Based on these problems, data calculations and analysis are carried out in the initial intersection condition, obtained saturated degree (DS) values of 0,983 in the morning and 0,937 in the afternoon. Because the results of the intersection calculation in the initial conditions did not comply the requirements of the Indonesian Highway Capacity Manual of 1997 (IHCM 1997), that's DS $<0,85$, it is necessary to recalculate with some alternative that value of DS can comply.
\end{abstract}

Keywords: intersection, congestion, degree of saturation, IHCM 1997. 


\section{PENDAhUlUAN}

Kota Bandung yang merupakan ibu kota propinsi Jawa Barat selalu mengalami peningkatan jumlah penduduk dan jumlah kendaraan setiap tahunnya. Akhir-akhir ini, sering terjadi permasalahan lalu lintas khususnya pada persimpangan jalan. Persimpangan merupakan suatu bagian jalan yang menjadi pusat pertemuan dari berbagai pergerakan arus lalu lintas. Pada tipe simpang tak bersinyal, sering dijumpai titik-titik konflik arus lalu lintas yang mengakibatkan kemacetan arus lalu lintas terutama pada saat jam-jam sibuk.

Contoh kasus terdapat di kota Bandung, terjadi pada persimpangan Jalan A.H. Nasution dan Jalan Cikadut. Lokasi ini dipilih karena selain kemacetan yang disebabkan oleh titik-titik konflik arus lalu lintas yang tidak teratur pada saat jam sibuk, di sekitar jalan pada simpang ini juga merupakan kawasan pertokoan, pemukiman, sekolah dan juga pom bensin yang merupakan tempat keluar masuk kendaraan pada daerah tersebut. Gambar 1 merupakan lokasi penelitian, Gambar 2.a dan 2.b merupakan beberapa gambaran kondisi pada simpang tersebut.
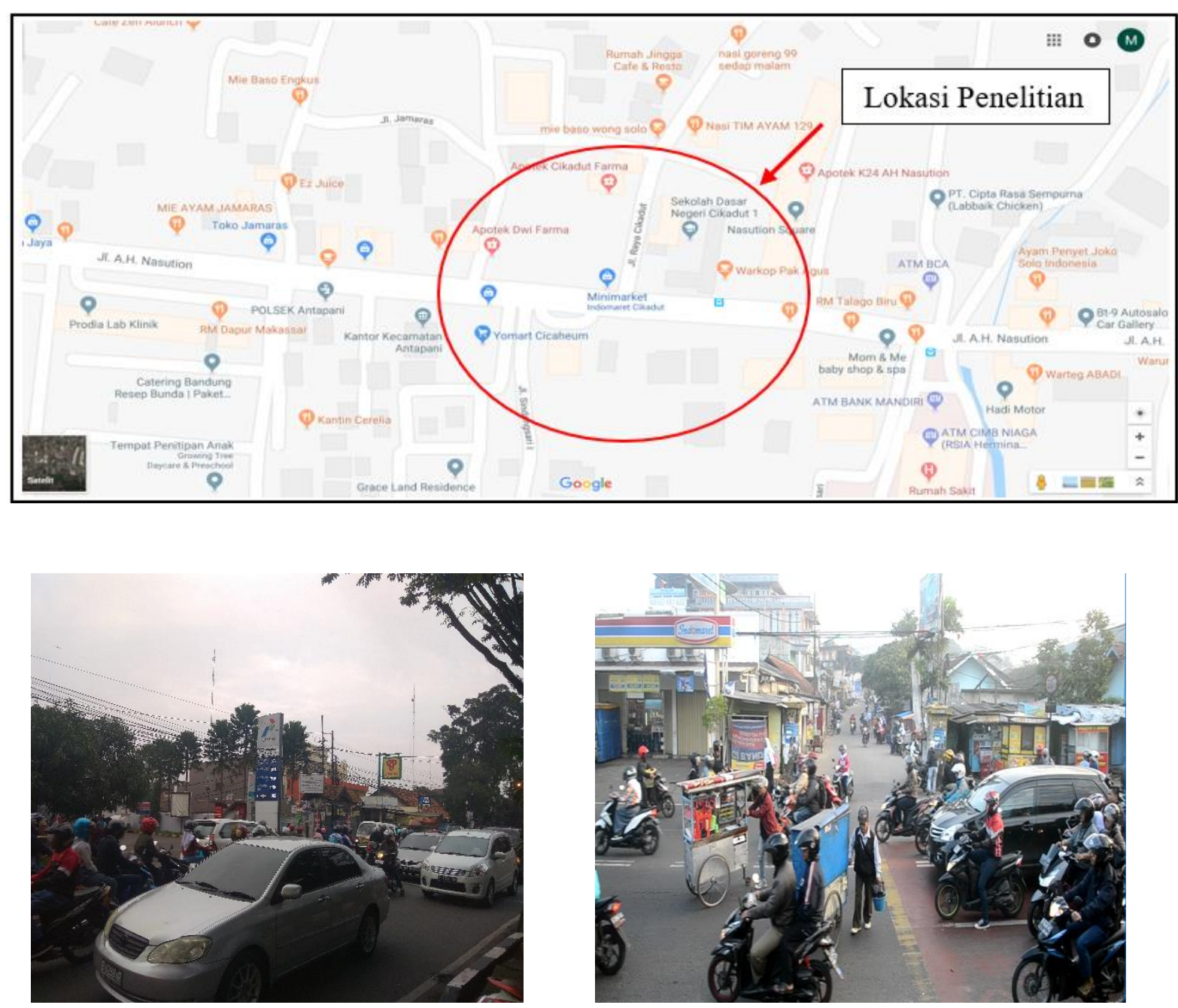

Gambar 1. Lokasi Penelitian

(a)

(b)

Gambar 2. Kondisi Jalan pada Simpang (Sumber: Survei Lapangan) 


\section{TINJAUAN PUSTAKA}

\subsection{Persimpangan}

Menurut Hendarto (2001), persimpangan adalah daerah dimana dua atau lebih jalan bergabung atau berpotongan/bersilangan. Menurut Hobbs (1995), persimpangan jalan merupakan simpul transportasi yang terbentuk dari beberapa pendekat dimana arus kendaraan dari beberapa pendekat tersebut bertemu dan memencar meninggalkan persimpangan tersebut. Menurut Abubakar (1995), persimpangan adalah simpul pada jaringan jalan dimana jalan-jalan bertemu dan lintasan kendaraan berpotongan. Lalu lintas pada masing-masing kaki persimpangan menggunakan ruang jalan pada persimpangan secara bersama-sama dengan lalu lintas lainnya.

\subsection{Jenis Simpang}

Jenis simpang Menurut Direktorat Jendral Bina Marga dalam Manual Kapasitas Jalan Indonesia (1997), pemilihan jenis simpang untuk suatu daerah sebaiknya berdasarkan pertimbangan ekonomi, pertimbangan keselamatan lalu lintas, dan pertimbangan lingkungan. Menurut Morlok (1988), jenis simpang berdasarkan cara pengaturannya dapat dikelompokkan menjadi 2 (dua) jenis, yaitu:

1. Simpang jalan tanpa sinyal, yaitu simpang yang tidak memakai sinyal lalu lintas. Pada simpang ini pemakai jalan harus memutuskan apakah mereka cukup aman untuk melewati simpang atau harus berhenti dahulu sebelum melewati simpang tersebut.

2. Simpang jalan dengan sinyal, yaitu pemakai jalan dapat melewati simpang sesuai dengan pengoperasian sinyal lalu lintas. Jadi pemakai jalan hanya boleh lewat pada saat sinyal lalu lintas menunjukkan warna hijau pada lengan simpangnya.

\subsection{Kapasitas Simpang Tak Bersinyal}

Menurut MKJI (1997) kapasitas total untuk semua lengan simpang adalah hasil perkalian antara kapasitas dasar $\left(C_{0}\right)$ yaitu kapasitas pada kondisi tertentu dan faktor-faktor penyesuaian $(F)$ dengan memperhitungkan pengaruh kondisi lapangan terhadap kapasitas. Bentuk model kapasitas dengan Persamaan 1 menjadi sebagai berikut :

$$
C=C_{0} * F_{W} * F_{M} * F_{C S} * F_{R S U} * F_{L T} * F_{R T} * F_{M I}
$$

\subsection{Derajat Kejenuhan (DS)}

Derajat kejenuhan (DS) merupakan rasio arus lalu lintas aktual [smp/jam] terhadap kapasitas [smp/jam] dapat dihitung dengan menggunakan Persamaan 2.

$$
D S=\frac{Q t o t}{C}
$$

\subsection{Tundaan}

Tundaan adalah waku tempuh tambahan yang diperlukan untuk melalui simpang. Tundaan pada simpang dapat terjadi karena dua sebab yaitu:

1. Tundaan Lalu Lintas (DT) terjadi karena interaksi lalu lintas dengan yang lain dalam simpang.

2. Tundaan Geometrik $(D G)$ akibat perlambatan dan percepatan kendaraan.

\subsubsection{Tundaan Lalu Lintas Rata-Rata Simpang $\left(D T_{I}\right)$}

Tundaan $D T_{I}$ ditentukan dari hubungan empiris antara tundaan $D T_{I}$ dan derajat kejenuhan $(D S)$.

Untuk $D S \leq 0,6$, dapat dihitung menggunakan Persamaan 3.

$$
D T=2+(8,2078 * D S)-[(1-D S) * 2]
$$


Untuk $D S>0,6$, dapat dihitung menggunakan Persamaan 4.

$$
D T=1,0504 \div(0,2742-0,2042 * D S)-[(1-D S) * 2]
$$

\subsubsection{Tundaan Lalu Lintas Rata-Rata Jalan Mayor $\left(D T_{M A}\right)$}

Tundaan lalu lintas rata-rata di jalan mayor merupakan tundaan lalu lintas rata-rata untuk seluruh kendaraan yang masuk simpang dari jalan mayor.

Untuk $D S \leq 0,6$, dapat dihitung menggunakan Persamaan 5.

$$
D T=1,8+5,8234 * D S-(1-D S) * 1,8
$$

Untuk $D S>0,6$, dapat dihitung menggunakan Persamaan 6.

$$
D T=1,05034 \div(0,346-0,246 * D S)-[(1-D S) * 1,8]
$$

\subsubsection{Tundaan Lalu Lintas Rata-Rata Jalan Minor ( $\left.D T_{M I}\right)$}

Tundaan lalu lintas rata-rata jalan minor ditentukan berdasarkan tundaan lalu lintas rata-rata di simpang $\left(D T_{I}\right)$ dan tundaan lalu lintas dijalan mayor $\left(D T_{M A}\right)$. Dapat dihitung dengan menggunakan Persamaan 7.

$$
D T_{M I}=\left(Q_{T O T} * D T_{I}-Q_{M A} * D T_{M A}\right) \div Q_{M I}
$$

\subsubsection{Tundaan Geometrik Simpang (DG)}

Tundaan geometrik simpang adalah tundaan yang diakibatkan oleh geometrik simpang. Untuk nilai $D S \geq 1,0$, maka nilai $D G=4$ detik/smp. Apabila nilai $D S \leq 1,0$, dapat dihitung dengan menggunakan Persamaan 8.

$$
D G=(1-D S) *(P T * 6+(1-P T) * 3)+D S * 4
$$

\subsubsection{Tundaan Simpang (D)}

Tundaan simpang dapat dihitung dengan menggunakan Persamaan 9.

$$
D=D G+D T_{I}
$$

\subsection{Peluang Antrian}

Rentang nilai peluang antrian ditentukan dari hubungan empiris antara peluang antrian dan derajat kejenuhan. Grafik hubungan peluang antrian dan derajat kejenuhan tersebut untuk menentukan persetase besarnya antrian kendaraan yang dapat dilihat pada Gambar 3.

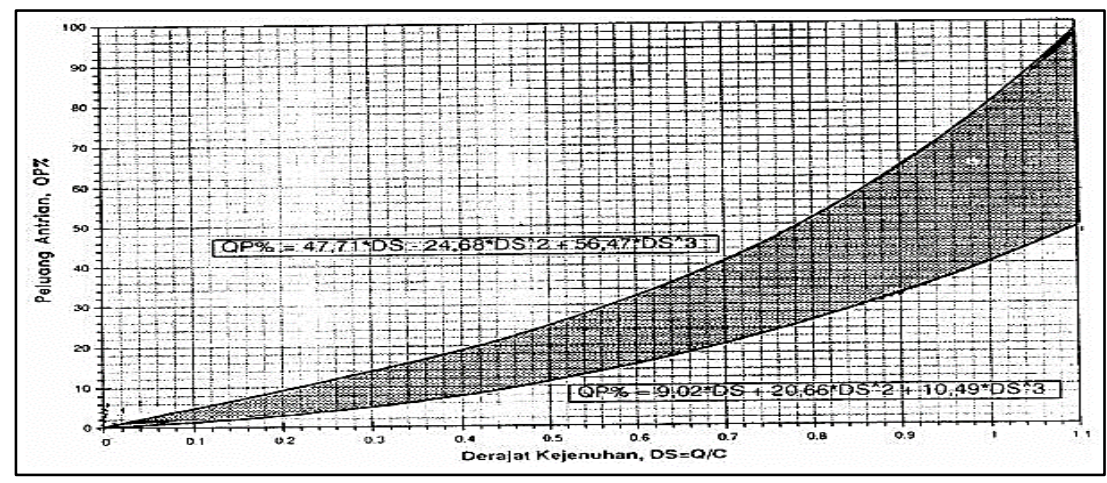

Gambar 3. Rentang peluang antrian terhadap derajat jenuh (Sumber: MKJI 1997) 


\section{METODE PENELITIAN}

\subsection{Tahapan Penelitian}

Tahap awal dalam penelitian ini adalah melakukan identifikasi masalah, yaitu untuk mengetahui permasalahan yang terjadi pada penelitian yang akan diambil, setelah diketahui masalah, lalu penelitian dikerjakan, lalu menenentukan apa topik/judul yang sesuai dengan permasalahan sebelumnya. Setelah itu melakukan survei pendahuluan, untuk mengetahui kondisi terkini pada lokasi penelitian tersebut, di antaranya yaitu kondisi lalu lintas, titik pengamatan, dan geometrik pada lokasi tersebut. Selanjutnya melakukan pengumpulan data, baik data primer maupun sekunder. Data yang telah diperoleh selanjutnya akan diolah untuk mengetahui hasil akhir dari penelitian yang akan dikerjakan serta dapat memberikan kesimpulan dan saran dalam penelitian tersebut.

\subsection{Pengumpulan Data}

Data yang dibutuhkan pada penelitian ini ada 2 jenis data yaitu, data primer, dan data sekunder. Data primer terdiri dari data volume lalu lintas kendaraan dan geometrik jalan yang diperoleh dari survei langsung di lapangan. Data sekunder adalah data yang diperoleh dari suatu instansi terkait ataupun dapat juga diperoleh dari internet, seperti data jumlah penduduk dan peta lokasi simpang pada penelitian ini yang bisa didapat dari internet.

\subsection{Analisis Data}

Analisis data dilakukan setelah memperoleh data primer dan data sekunder, selanjutnya dilakukan perhitungan menggunakan rumus, tabel, maupun grafik yang terdapat pada MKJI 1997. Hasil akhir perhitungan nanti akan diketahui apakah yang harus dilakukan pada simpang tersebut.

\section{HASIL DAN PEMBAHASAN}

\subsection{Data Arus Lalu Lintas}

Pengambilan data arus lalu lintas adalah berdasarkan data hasil survei dilapangan yang dilakukan dalam dua kali pemilihan waktu yaitu pagi pada jam 06.00-08.00 WIB, dan sore pada jam 16.00-18.00 WIB, yang ditentukan berdasarkan jam sibuk. Data volume lalu lintas dapat dilihat pada Tabel $\mathbf{1}$ dan Tabel $\mathbf{2}$ berikut.

Tabel 1. Data Arus Lalu Lintas Pagi

\begin{tabular}{|c|c|c|c|c|c|}
\hline \multirow[b]{2}{*}{$\begin{array}{c}\text { Kode } \\
\text { Simpang }\end{array}$} & \multirow{2}{*}{$\begin{array}{l}\text { Arah Tujuan } \\
\text { Pergerakan }\end{array}$} & \multicolumn{4}{|c|}{ Jenis Kendaraan } \\
\hline & & $\begin{array}{c}\text { Sepeda Motor } \\
\text { [knd/jam] }\end{array}$ & $\begin{array}{c}\text { Kendaraan } \\
\text { Ringan } \\
\text { [knd/jam] }\end{array}$ & $\begin{array}{c}\text { Kendaraan } \\
\text { Berat } \\
\text { [knd/jam] }\end{array}$ & $\begin{array}{c}\text { Kendaraan Tak } \\
\text { Bermesin } \\
\text { [knd/jam] }\end{array}$ \\
\hline \multirow{3}{*}{ JL. Minor C } & LT & 127 & 45 & 0 & 3 \\
\hline & RT & 178 & 46 & 0 & 5 \\
\hline & Total & 305 & 91 & 0 & 8 \\
\hline \multirow{3}{*}{ JL. Mayor A } & ST & 1941 & 442 & 18 & 15 \\
\hline & RT & 140 & 14 & 0 & 1 \\
\hline & Total & 2.081 & 456 & 18 & 16 \\
\hline \multirow{3}{*}{ JL. Mayor B } & LT & 95 & 32 & 0 & 3 \\
\hline & ST & 1486 & 395 & 14 & 4 \\
\hline & Total & 1.581 & 427 & 14 & 7 \\
\hline
\end{tabular}


Tabel 2. Data Arus Lalu Lintas Sore

\begin{tabular}{|c|c|c|c|c|c|}
\hline \multirow[b]{2}{*}{$\begin{array}{l}\text { Kode } \\
\text { Simpang }\end{array}$} & \multirow[b]{2}{*}{$\begin{array}{l}\text { Arah Tujuan } \\
\text { Pergerakan }\end{array}$} & \multicolumn{4}{|c|}{ Jenis Kendaraan } \\
\hline & & $\begin{array}{c}\text { Sepeda Motor } \\
\text { [knd/jam] }\end{array}$ & $\begin{array}{c}\text { Kendaraan } \\
\text { Ringan } \\
\text { [knd/jam] }\end{array}$ & $\begin{array}{c}\text { Kendaraan } \\
\text { Berat } \\
\text { [knd/jam] }\end{array}$ & $\begin{array}{c}\text { Kendaraan Tak } \\
\text { Bermesin } \\
\text { [knd/jam] }\end{array}$ \\
\hline \multirow{3}{*}{ JL. Minor C } & LT & 142 & 31 & 0 & 2 \\
\hline & RT & 204 & 34 & 0 & 1 \\
\hline & Total & 346 & 65 & $\mathbf{0}$ & 3 \\
\hline \multirow{3}{*}{ JL. Mayor A } & ST & 1.444 & 348 & 7 & 2 \\
\hline & RT & 184 & 47 & 0 & 2 \\
\hline & Total & 1.628 & 395 & 7 & 4 \\
\hline \multirow{3}{*}{ JL. Mayor B } & LT & 180 & 65 & 0 & 2 \\
\hline & ST & 1.719 & 444 & 7 & 1 \\
\hline & Total & 1.899 & 509 & 7 & 3 \\
\hline
\end{tabular}

\subsection{Perhitungan Simpang Tak Bersinyal}

\subsubsection{Lebar Pendekat dan Tipe Simpang}

Lebar pendekat pada jalan minor dan jalan mayor didapat dari hasil survei di lapangan. Tipe simpang menunjukan jumlah lengan simpang dan jumlah jalur pada jalan mayor dan jalan minor. Lebar pendekat dan tipe simpang dapat dilihat pada Tabel 3.

Tabel 3. Lebar Pendekat dan Tipe Simpang

\begin{tabular}{|c|c|c|c|c|c|c|c|c|c|}
\hline \multirow{3}{*}{ Alt } & \multirow{3}{*}{$\begin{array}{c}\text { Jml } \\
\text { Lengan }\end{array}$} & \multicolumn{5}{|c|}{ Lebar Pendekat [meter] } & \multicolumn{2}{|c|}{ Jumlah Lajur } & \multirow[b]{2}{*}{$\begin{array}{c}\text { Tipe } \\
\text { Simpang }\end{array}$} \\
\hline & & $\begin{array}{l}\text { Jalan } \\
\text { Minor }\end{array}$ & \multicolumn{3}{|c|}{ Jalan Utama } & $\begin{array}{c}\text { Lebar } \\
\text { Pendekat }\end{array}$ & $\begin{array}{l}\text { Jalan } \\
\text { Minor }\end{array}$ & $\begin{array}{l}\text { Jalan } \\
\text { Mavor }\end{array}$ & \\
\hline & & WC & WA & WB & WAB $/ 2$ & & & & \\
\hline 1 & 3 & 2,25 & 4 & 4 & 4 & 3,125 & 3 & 4 & 324 \\
\hline
\end{tabular}

\subsubsection{Kapasitas Persimpangan dan Faktor Penyesuaian}

Berikut rekapitulasi kapasitas serta faktor penyesuaian simpang pada Tabel 4 dan Tabel 5.

Tabel 4. Kapasitas Simpang pada Pagi Hari

\begin{tabular}{cccccccccc} 
Alternatif & $\begin{array}{c}\boldsymbol{C}_{\boldsymbol{0}} \\
{[\mathbf{s m p} / \text { jam }]}\end{array}$ & $\boldsymbol{F}_{\boldsymbol{W}}$ & $\boldsymbol{F}_{\boldsymbol{M}}$ & $\boldsymbol{F}_{\boldsymbol{C S}}$ & $\boldsymbol{F}_{\boldsymbol{R S U}}$ & $\boldsymbol{F}_{\boldsymbol{L T}}$ & $\boldsymbol{F}_{\boldsymbol{R} T}$ & $\boldsymbol{F}_{\boldsymbol{M I}}$ & $\begin{array}{c}\boldsymbol{C} \\
\text { [smp/jam] }\end{array}$ \\
1-pagi & 3.200 & 0,968 & 1,00 & 1,00 & 0,93 & 0,941 & 1,023 & 1,101 & 3.051 \\
\hline
\end{tabular}

Tabel 5. Kapasitas Simpang pada Sore Hari

\begin{tabular}{cccccccccc}
\hline Alternatif & $\begin{array}{c}\boldsymbol{C}_{\mathbf{0}} \\
{[\mathbf{s m p} / \mathbf{j a m}]}\end{array}$ & $\boldsymbol{F}_{\boldsymbol{W}}$ & $\boldsymbol{F}_{\boldsymbol{M}}$ & $\boldsymbol{F}_{\boldsymbol{C S}}$ & $\boldsymbol{F}_{\boldsymbol{R S U}}$ & $\boldsymbol{F}_{\boldsymbol{L T}}$ & $\boldsymbol{F}_{\boldsymbol{R} T}$ & $\boldsymbol{F}_{\boldsymbol{M I}}$ & $\begin{array}{c}\boldsymbol{C} \\
\text { [smp/jam }]\end{array}$ \\
\hline 1-sore & 3.200 & 0,968 & 1,00 & 1,00 & 0,93 & 0,982 & 1,003 & 1,101 & 3.122 \\
\hline
\end{tabular}

\subsubsection{Kinerja Simpang Tak Bersinyal}

Berikut merupakan rekapitulasi data yang tersaji pada Tabel 6 dan Tabel 7.

Tabel 6. Kinerja Simpang Tak Bersinyal pada Pagi Hari

\begin{tabular}{|c|c|c|c|c|c|c|c|c|}
\hline Alternatif & $Q$ & $D S$ & DTi & $D T_{M A}$ & $D T_{M I}$ & $D G$ & $D$ & $Q P$ \\
\hline & [smp/jam] & $Q t o t / C$ & & & [dtk/smp & & & [\%] \\
\hline 1-pagi & 2.999 & 0,983 & 14,261 & 10,050 & 61,916 & 3,990 & 18,251 & $39-77 \%$ \\
\hline
\end{tabular}


Tabel 7. Kinerja Simpang tak Bersinyal pada Sore Hari

\begin{tabular}{|c|c|c|c|c|c|c|c|c|}
\hline Alternatif & $Q$ & $D S$ & DTi & $D T_{M A}$ & $D T_{M I}$ & $D G$ & $D$ & $Q P$ \\
\hline & [smp/jam] & Qtot $/ C$ & & & dtk/smp] & & & [\%] \\
\hline 1-sore & 2.924 & 0,937 & 12,535 & 8,971 & 52,755 & 3,971 & 16,507 & $35-69 \%$ \\
\hline
\end{tabular}

Berdasarkan perhitungan simpang tak bersinyal di atas, didapat nilai derajat jenuh sebesar 0,983 pada pagi hari dan 0,937 pada sore hari. Berdasarkan hasil tersebut, nilai $D S$ tidak memenuhi persyaratan MKJI 1997 simpang tak bersinyal, baik pada pagi hari ataupun sore hari yaitu sebesar $D S>0,85$. Maka untuk mengurangi derajat jenuh pada simpang tersebut, dilakukan alternatif penanganan yang kedua, yaitu pelarangan belok kanan pada simpang dengan menggunakan median pada Jalan A.H. Nasution.

\subsection{Alternatif Penanganan Simpang Tak Bersinyal (Pelarangan Belok Kanan pada \\ Simpang dengan Menggunakan Median pada Jalan A.H. Nasution) \\ Percobaan perhitungan dengan alternatif kedua yaitu pelarangan belok kanan pada simpang dengan menggunakan median pada Jalan A.H. Nasution didapat hasil kapasitas yang dapat dilihat pada Tabel 8 dan Tabel 9.}

Tabel 8. Kapasitas Simpang pada Pagi Hari dengan Alternatif Kedua

\begin{tabular}{cccccccccc}
\hline Alternatif & $\begin{array}{c}\boldsymbol{C}_{\boldsymbol{0}} \\
\text { [smp/jam] }\end{array}$ & $\boldsymbol{F}_{\boldsymbol{W}}$ & $\boldsymbol{F}_{\boldsymbol{M}}$ & $\boldsymbol{F}_{\boldsymbol{C S}}$ & $\boldsymbol{F}_{\boldsymbol{R S U}}$ & $\boldsymbol{F}_{\boldsymbol{L} \boldsymbol{T}}$ & $\boldsymbol{F}_{\boldsymbol{R} \boldsymbol{T}}$ & $\boldsymbol{F}_{\boldsymbol{M I}}$ & $\begin{array}{c}\boldsymbol{C} \\
\text { [smp/jam }]\end{array}$ \\
\hline 1-pagi & 3.200 & 0,968 & 1,00 & 1,00 & 0,93 & 0,941 & 1,023 & 1,101 & 3.051 \\
\hline 2-pagi & 3.200 & 0,968 & 1,05 & 1,00 & 0,93 & 1,013 & 1,090 & 1,101 & 3.676 \\
\hline
\end{tabular}

Tabel 9. Kapasitas Simpang pada Sore Hari dengan Alternatif Pertama

\begin{tabular}{cccccccccc} 
Alternatif & $\begin{array}{c}\boldsymbol{C}_{\mathbf{0}} \\
\text { [smp/jam] }\end{array}$ & $\boldsymbol{F}_{\boldsymbol{W}}$ & $\boldsymbol{F}_{\boldsymbol{M}}$ & $\boldsymbol{F}_{\boldsymbol{C S}}$ & $\boldsymbol{F}_{\boldsymbol{R S U}}$ & $\boldsymbol{F}_{\boldsymbol{L T}}$ & $\boldsymbol{F}_{\boldsymbol{R} \boldsymbol{T}}$ & $\boldsymbol{F}_{\boldsymbol{M I}}$ & $\begin{array}{c}\boldsymbol{C} \\
\text { [smp/jam }]\end{array}$ \\
\hline 1-sore & 3.200 & 0,968 & 1,00 & 1,00 & 0,93 & 0,982 & 1,003 & 1,101 & 3.122 \\
\hline 2-sore & 3.200 & 0,968 & 1,05 & 1,00 & 0,93 & 1,056 & 1,090 & 1,101 & 3.831 \\
\hline
\end{tabular}

Setelah menghitung nilai kapasitas tersebut, didapat hasil perhitungan kinerja simpang yang dapat dilihat pada Tabel $\mathbf{1 0}$ dan Tabel $\mathbf{1 1}$.

Tabel 10. Kinerja Simpang Tak Bersinyal pada Pagi Hari dengan Alternatif Kedua

\begin{tabular}{cccccccccc}
\hline Alternatif & $\begin{array}{c}\boldsymbol{Q} \\
\text { [smp/jam] }\end{array}$ & $\begin{array}{c}\boldsymbol{D} \boldsymbol{S} \\
\boldsymbol{Q} \text { tot } / \boldsymbol{C}\end{array}$ & $\boldsymbol{D T i}$ & $\boldsymbol{D T}_{\boldsymbol{M A}}$ & $\begin{array}{c}\boldsymbol{D} \boldsymbol{T}_{\boldsymbol{M I}} \\
{[\mathbf{d t k} / \mathbf{s m p}]}\end{array}$ & $\boldsymbol{D G}$ & $\boldsymbol{D}$ & $\boldsymbol{Q P}$ \\
\hline 1-pagi & 2.999 & 0,983 & 14,261 & 10,050 & 61,916 & 3,990 & 18,251 & $39-77 \%$ \\
\hline 2-pagi & 2.999 & 0,816 & 9,393 & 6,897 & 37,641 & 3,891 & 13,284 & $27-53 \%$ \\
\hline
\end{tabular}

Tabel 11. Kinerja Simpang Tak Bersinyal pada Sore Hari dengan Alternatif Kedua

\begin{tabular}{|c|c|c|c|c|c|c|c|c|}
\hline Alternatif & $Q$ & $D S$ & DTi & $D T_{M A}$ & $D T_{M I}$ & $D G$ & $D$ & $Q P$ \\
\hline & [smp/jam] & $Q t o t / C$ & \multicolumn{5}{|c|}{ [dtk/smp] } & [\%] \\
\hline 1-sore & 2.924 & 0,937 & 12,535 & 8,971 & 52,755 & 3,971 & 16,507 & $35-69 \%$ \\
\hline 2-sore & 2.924 & 0,763 & 8,400 & 6,210 & 33,112 & 3,892 & 12,292 & $24-47 \%$ \\
\hline
\end{tabular}

Berdasarkan hasil perhitungan dengan alternatif kedua yaitu pelarangan belok kanan pada simpang dengan menggunakan median pada Jalan A.H. Nasution didapat nilai kapasitas 
pada simpang tersebut bertambah besar pada pagi hari yaitu sebesar $3.676 \mathrm{smp} / \mathrm{jam}$, dan sore hari sebesar $3.831 \mathrm{smp} / \mathrm{jam}$. Kemudian kinerja simpang tersebut pada pagi hari didapat nilai derajat jenuh $(D S)$ sebesar 0,816 dengan tundaan simpang sebesar 13,284 dtk/smp dan peluang antrian yang dapat terjadi sebesar $27-53 \%$, lalu pada sore hari sebesar 0,763 dengan tundaan simpang sebesar $12,292 \mathrm{dtk} / \mathrm{smp}$ dan peluang antrian yang dapat terjadi sebesar 24-47\%. Hasil ini sudah memenuhi persyaratan MKJI 1997, yaitu sebesar DS < 0,85.

\section{KESIMPULAN}

Kesimpulan yang dapat diperoleh berdasarkan hasil analisis dan pembahasan di antaranya adalah pada kondisi awal simpang diperoleh nilai derajat jenuh sebesar 0,983 untuk pagi hari dan 0,937 untuk sore hari. Hasil tersebut tidak memenuhi persyaratan MKJI 1997, karena derajat kejenuhannya $(D S)>0,85$. Lalu dilakukan perhitungan ulang dengan alternatif kedua yaitu pelarangan belok kanan pada simpang dengan menggunakan median pada Jalan A.H. Nasution. Dari hasil perhitungan alternatif kedua tersebut terdapat penurunan pada derajat jenuh, yaitu sebesar 0,816 untuk pagi hari dan 0,763 untuk sore hari. Hasil tersebut sudah memenuhi persyaratan pada MKJI 1997, yaitu derajat jenuh (DS) $<0,85$. Penerapan pelarangan belok kanan pada simpang dengan menggunakan median pada Jalan A.H. Nasution terbukti dapat mengurangi derajat kejenuhan pada simpang tersebut.

\section{DAFTAR RUJUKAN}

Abubakar. (1995). Sistim Transportasi Kota. Jakarta: Direktur Jendral Perhubungan Darat.

Direktorat Jenderala Bina Marga. (1997). Manual Kapasitas Jalan Indonesia. Jakarta: Departemen Pekerjaan Umum

Hendarto, S. (2001). Dasar-Dasar Transportasi. Bandung: ITB.

Hobbs, F. D. (1995). Perencanaan dan Teknik Lalu Lintas. Yogyakarta: Gadjah Mada University Press.

Morlok, E. K. (1988). Pengantar Teknik dan Perencanaan Transportasi. Jakarta: Erlangga. 